\title{
La activación de conocimientos previos (ACP): una estrategia de comprensión lectora
}

\author{
$\mathrm{M}^{\mathrm{a}}$ Teresa LlamAZARES PRIETO \\ Departamento de Filología Hispánica y Clásica \\ Universidad de León \\ mtllap@unileon.es
}

Recibido: 13 de mayo de 2014

Aceptado: 15 de abril de 2015

RESUMEN. El objetivo de este artículo es presentar un estudio sobre la activación de conocimientos previos como una de las estrategias que los docentes utilizan para trabajar la comprensión lectora con alumnos de segundo y tercero de Educación Primaria. Los datos que se analizan han sido recogidos mediante observaciones realizadas, durante dos cursos, en diversas aulas de la geografía española. Como resultado del análisis, se ofrece una panorámica de las maneras de activar conocimientos previos y cómo se distribuyen en función del tipo de texto y de la finalidad de la lectura.

Palabras clave: Activación de conocimientos previos, comprensión lectora, prácticas docentes, estrategias de comprensión.

\section{The activation of previous knowledge: A reading comprehension strategy}

\begin{abstract}
The aim of this paper is to present the results of a study on the activation of previous knowledge as one of the strategies that teachers use to develop second and third year primary students' reading skills. The data for the analysis were collected through the observations made in some classrooms belonging to different Spanish schools over a twoyear period. As a result of the analysis, an overview is offered of a number of ways to activate previous knowledge and of their distribution according to the type of text and the reading purpose.
\end{abstract}

Key words: activation of previous knowledge, reading comprehension, teaching practices, comprehension strategies.

\section{L'activation de connaissances préalables: Une stratégie de compréhension lectrice}

RÉSUMÉ. Le but de cet article est de présenter une étude sur l'activation de connaissances préalables comme une des stratégies que les enseignants utilisent pour travailler la compréhension lectrice avec des élèves des Cours Élementaires (CE1 et CE2) de l'Éducation Primaire. Les données qu'on analyse ont été obtenues à partir d'observations réalisées, pendant deux cours scolaires, dans diverses classes de la géographie espagnole. 
Comme résultat de l'analyse, on présente une vue d'ensemble des façons d'activer les connaissances préalables et comment elles se distribuent en fonction du type de texto et de l'objectif de la lecture.

Mots-clés: Activation de connaissances préalables, compréhension lectrice, pratiques d'enseignement, stratégies de compréhension.

SUMARIO: 1. Marco teórico; 2. Diseño de la investigación; 2.1. Objetivos e hipótesis; 2.2. Tipo de investigación; 2.3. Método; 3. Resultados obtenidos; 4. Discusión de resultados; 5. Conclusiones; 6. Bibliografía.

\section{MARCO TEÓRICO}

Una de las estrategias consideradas clave en la comprensión lectora es la activación de conocimientos previos. En este trabajo tratamos de describir e interpretar actividades docentes que tienen como objetivo esa activación. Para ello, hemos tomado una muestra de actividades en las aulas, desarrolladas durante el segundo y tercer curso de Educación Primaria, momento en el que, tras haber superado ya el aprendizaje inicial de la lectura, se produce un acusado progreso en la comprensión lectora. Por esta razón, quisimos observar y analizar qué estrategias de comprensión lectora se ponen en marcha en las actividades realizadas.

Actualmente, la lectura es entendida como una actividad básica para la construcción de saberes, porque integra y reestructura diversidad de conocimientos, a la vez que exige la participación del lector, que es el responsable de la atribución de significados y de la formulación de interpretaciones, además de ser, personalmente, quien fija la ordenación cognitiva de las estructuras y referentes textuales (Mendoza Fillola, 1998). La lectura, así concebida, implica una transacción entre el lector y el texto, de tal modo que las características y conocimientos previos del lector son tan importantes para la comprensión como las características del texto (Colomer y Camps, 1996). La lectura comprensiva requiere que el lector sea capaz de integrar dicha información en unidades de sentido global, en una representación del contenido del texto que es mucho más que la suma de los significados individuales de las palabras (De Vega et al. 1990; Vidal Abarca, 1998). En efecto, más que la posesión del conocimiento, lo que marca la diferencia en la comprensión es la capacidad para usar ese conocimiento integrando los distintos componentes del texto con lo que el lector trae consigo (Perrussi, Brandao y Oakhill, 2005; Cain, Oakhill, Barnes y Bryant, 2001, citado en Perrussi, Brandao y Oakhill, 2005). Durante la lectura comprensiva, el lector infiere información, es decir, comprende algún aspecto determinado del texto a partir del significado de otro o completa el significado de algún aspecto del texto con información que posee, pero que no está verbalizada en el texto.

Este estudio se asienta en el modelo interactivo que considera que leer es una actividad cognitiva compleja que nos permite comprender e interpretar textos escritos de diverso tipo con diferentes intenciones y objetivos (Solé, 2006). Cuando el lector se enfrenta a un texto, obtiene información de los diferentes elementos que lo com- 
ponen (letras, palabras...), información que, a través de un proceso ascendente, se propaga hacia niveles más elevados. Simultáneamente, se da un proceso descendente de verificación de las expectativas creadas acerca del significado global del texto, utilizando indicadores de tipo léxico, sintáctico y grafo-fónico. De esta manera, el lector pone en juego, a la vez, su conocimiento del mundo y su conocimiento del texto para comprender el significado de lo que lee, lo que, por otra parte, contribuirá a acrecentar sus conocimientos anteriores. Desde el punto de vista de la enseñanza, las propuestas que se basan en este modelo señalan la necesidad de que los alumnos aprendan a procesar el texto y sus distintos elementos, así como las estrategias que harán posible su comprensión.

Las afirmaciones anteriores explican que la capacidad de comprender e interpretar autónomamente textos escritos y la posibilidad de enseñar a hacerlo hayan pasado a considerarse los aspectos clave de la lectura y de su enseñanza (Colomer y Camps, 1990, 54). Enseñar a comprender textos escritos en contextos educativos consiste en asistir al lector novel en el uso de una serie de estrategias que le permiten construir el sentido global del texto escrito (Solé, 2006; Sánchez, 1998). La construcción conceptual es muy relevante en los planteamientos didácticos, ya que la capacidad de comprender compensa en muchas ocasiones las dificultades de lectura que los niños puedan tener (Adams, Bell y Perfetti, 1995). Por otro lado, la comprensión podría verse facilitada por un determinado género. Desde los trabajos pioneros de Van Dijk y Kintsh (1983) y Adam (1985), entre otros, sabemos que los diferentes tipos de texto poseen unas formas de organización discursiva que condicionan la interpretación del lector. Ciertas organizaciones discursivas, como la de los textos narrativos, facilitan la comprensión y la formulación de cierto tipo de inferencias (Bruner, 1988; Wells, 1988; Fayol, 1991).

Leer, por tanto, no es descodificar, aunque para leer sea necesario descodificar. Esta afirmación implica:

- La presencia de un lector activo que procesa y atribuye significado a lo que está escrito relacionándolo con lo que ya sabe, es decir, sus conocimientos previos, y modificando estos como consecuencia de su actividad.

- Tener en cuenta que, en la comprensión de un texto intervienen la forma y el contenido del mismo, así como las expectativas y los conocimientos previos del lector. El significado o sentido del texto se construye por parte del lector, no es una réplica del significado que el autor quiso imprimirle, sino una construcción en la que intervienen el significado del texto, los conocimientos previos del lector que lo aborda y los objetivos que persigue.

- Conocer que, para procesar activamente un texto, utilizamos distintas estrategias que nos permiten verificar las predicciones y las hipótesis que vamos formulando constantemente durante la lectura para llegar a construir una interpretación de su significado. Si la escuela quiere formar buenos lectores, debe enseñar este proceso interno $\mathrm{y}$, en gran medida, inconsciente. 
Hablar de operaciones y actividades cognitivas para leer, requiere hablar de estrategias que permitan el uso o el desarrollo de dichas operaciones. El término estrategias nos puede ayudar a determinar de forma más analítica los procesos o microprocesos que convierten el acto lector en un acto de comprensión, de acuerdo con las propias necesidades del lector. Pero, ¿a qué llamamos estrategias de comprensión lectora? Las estrategias de comprensión lectora son procedimientos de carácter elevado, que implican la presencia de objetivos que cumplir, la planificación de las acciones que se desencadenan para lograrlos, así como su evaluación y posible cambio (lo que nos permite seleccionar o abandonar determinadas acciones para conseguir una meta) (Solé, 2006, 59). Cuando los educandos poseen metaconocimientos sobre las estrategias de comprensión, que surgen cuando el docente modela procesos de comprensión o guía los procesos de forma colectiva y reflexiona sobre ellos, la comprensión lectora aumenta, como lo demuestran los estudios de Navarro y Mora (2009).

Una de las estrategias que Palincsar y Brown (1984) han señalado como imprescindible es la de aportar a la lectura los conocimientos previos pertinentes para el contenido de que se trate, estrategia en la que coinciden Solé (2006) cuando habla de actualizar el conocimiento previo de los lectores, Sim-Sim y Viana (2007) cuando se refieren a relacionar información leída con conocimientos exteriores al texto o Vidal-Abarca y Martínez (1998) cuando señalan la necesidad de relacionar las nuevas ideas con las anteriores. Vidal-Abarca (2011) añade un matiz importante cuando habla de interpretar las ayudas textuales para relacionar ideas.

No se trataría de añadir nuevos conocimientos, sino de activar los conocimientos relevantes que el lector ya posee. Advierten Vidal-Abarca y Martínez (1998), que la intervención pedagógica dirigida a activar conocimientos previos no debería focalizarse en contenidos específicos, sino que debería dirigirse hacia los esquemas de interpretación (o constructos psicológicos) que subyacen a la comprensión. Hay una relación directa entre la capacidad de comprensión de un texto y los conocimientos previos relacionados con el contenido del mismo que el lector posea: cuantos más conocimientos se tengan $-\mathrm{y}$ mejores estrategias se posean- mejor se desarrollará el proceso de comprensión. Y a la inversa: cuanto menor sea el conocimiento y peores estrategias se hayan adquirido, más costoso será el proceso y más probabilidades de que no se logre una buena comprensión (Vidal-Abarca y Martínez, 1998).

En síntesis, este artículo se asienta sobre el modelo interactivo de la comprensión lectora. Entendemos que la comprensión de un texto escrito requiere un proceso constructivo, en el cual los datos que figuran en el texto son tan importantes como la información previa disponible en la memoria (conocimiento conceptual) (De Vega et al. 1990). Este modelo se traslada también a nuestra concepción de la enseñanza de la lectura, puesto que asumimos que, enseñar a leer, es ayudar al lector a establecer relaciones entre los conocimientos aportados por el texto y sus propios conocimientos e incentivar constantemente la búsqueda de significados particulares y compartidos. 


\section{DISEÑO DE LA INVESTIGACIÓN}

\subsection{Objetivos e hipótesis}

Ya que se ha establecido que la activación de conocimientos previos es una de las estrategias clave para la comprensión lectora (Acquaroni Muñoz, 2004; Solé 2006), queremos saber:

- Si aparece en las prácticas docentes. Dicho de otra manera, en las aulas de $2^{\circ}$ y $3^{\circ}$ de Educación Primaria, en las que hemos hecho observaciones, ¿se activan los conocimientos previos para ayudar a comprender un texto?

- Cómo aparece, es decir, si lo anterior ocurre, ¿se hace con todos los tipos de texto por igual?, ¿en unos más que en otros?, ¿de una manera en unos y de otra manera en otros?

No pretendemos establecer un inventario del que se puedan obtener resultados generalizables y estadísticamente significativos (para ello habríamos de trabajar con un conjunto más amplio de datos): nuestro objetivo principal es que las aportaciones de todo el proceso investigador reviertan en el conocimiento teórico-práctico de los profesionales de la docencia; queremos mostrar, especialmente a los docentes en formación, lo que sucede en una muestra de aulas para guiarlos en el análisis de situaciones de enseñanza-aprendizaje. Lo que pretendemos, en definitiva, es trasladar resultados y procedimientos de investigación en las aulas de Educación Primaria a la formación inicial del profesorado.

\subsection{Tipo de investigación}

El estudio forma parte del proyecto de investigación interuniversitario Las condiciones del aprendizaje de la comprensión lectora (EDU2009-10321) ${ }^{1}$, cuya finalidad es detectar las habilidades de los alumnos y las prácticas docentes que mejor contribuyen a explicar el progreso en la comprensión lectora al comienzo de la escuela primaria. Se trata de una investigación longitudinal que combina las aproximaciones cuantitativa y cualitativa, tanto para la obtención como para el análisis de los datos. Esta combinación es consecuencia de haber optado por abordar un objeto de estudio extremadamente complejo en los contextos naturales en los que tiene lugar, con la voluntad de acceder a los distintos aspectos que inciden en él (Tolchinsky y Solé, 2009). Además, nos permite compartir el marco de referencia con

\footnotetext{
${ }^{1}$ Proyecto subvencionado por el MICINN en el Plan Nacional de I+D+I (2008-2011), cuyo equipo investigador estuvo conformado por: Liliana Tolchinsky (I.P.) (Universitat de Barcelona) C. Buisán, M. Albert, C. Castillo (Universitat de Barcelona), P. Fernández, T. Chamorro, I. Ga . Parejo (Universidad Complutense de Madrid), L. Barrio (Universidad de Valladolid), T. Llamazares, $M^{a}$ D. Alonso-Cortés (Universidad de León), I. Ríos, D. Mallén (Universitat Jaume I), I. Gallardo (Universitat de València), C. Barragán (Universidad de Almería), X. A. Glez. Riaño (Universidad de Oviedo), S. Sánchez (Universidad de Cantabria/Universidad de Cádiz), M. Bilbatua, y D. Egizabal (Mondragón Unibertsitatea).
} 
quienes tienen la responsabilidad de llevar a cabo la actuación concreta en las aulas, para incidir en la competencia en comprensión lectora de los niños.

Este proyecto se basa en un proyecto anterior que se proponía determinar la influencia relativa de las prácticas docentes vigentes y de los conocimientos previos de los niños en el aprendizaje inicial de la lengua escrita (APILE- SEJ1200605292) $)^{2}$.

\subsection{Método}

\section{Participantes}

La investigación se llevó a cabo en aulas de las diversas zonas geográficas donde se ubican los investigadores del proyecto, durante los cursos 2009-2010 (cuando el alumnado cursaba $2^{\circ}$ de Educación Primaria) y 2010-2011 (cuando ese mismo alumnado cursaba $3^{\circ}$ ), tanto en colegios públicos como concertados. Al cargo de cada una de esas aulas, 27 cada curso, había una maestra-tutora. La mayoría de los niños que configuran la muestra del proyecto APICLE sobre comprensión lectora habían sido objeto de seguimiento en el marco del proyecto anterior (APILE).

\section{Procedimiento}

Para la recogida de datos se utiliza la observación natural, sin mediación del observador. Este tipo de observación permite registrar las actividades que se realizan en el aula captando, además, los pormenores y matices que emergen en su desarrollo ya que suponemos que las maneras de trabajar en el aula pueden ser importantes a la hora de explicar los rendimientos (Anguera, 1983).

Cada investigador realizó tres observaciones de aula en $2^{\circ}$ curso y otras tres en $3^{\circ}$, una por trimestre, observaciones que se recogían en una tabla donde se anotaba (además del día y la hora, el colegio...) lo que ocurría en el aula, sin intervenir ni interpretar en ningún momento la situación observada. Se recogía la dinámica de la tarea, anotando si se trataba de una tarea específicamente destinada a la comprensión lectora o si era una tarea que, no estando específicamente diseñada para el desarrollo de la comprensión lectora, sí la requería. También se indicaban las estrategias que, para el desarrollo de dicha habilidad, los docentes ponían en marcha en cada actividad y, para cada una de ellas, se señalaba si se utilizaba antes, durante o después de la lectura. El modelo de tabla era el siguiente:

${ }^{2}$ Una información exhaustiva de este proyecto se puede encontrar en el volumen 24(4), 2012, de la revista Cultura y Educación, monográfico dedicado al Aprendizaje inicial de la lengua escrita: prácticas docentes y conocimientos de los alumnos, coordinado por S. Sánchez y M.D. Alonso-Cortés. Para una descripción conjunta de ambos proyectos conocidos como APILE y APICLE, ver Sánchez Rodríguez, Llamazares Prieto y Alonso-Cortés Fradejas (2011). 


\begin{tabular}{|c|c|c|l|lr|}
\hline \multicolumn{2}{|c|}{ OBSERVACIONES } & \multicolumn{1}{c|}{$\begin{array}{c}\text { Estrategias que } \\
\text { utiliza la maestra }\end{array}$} & \multicolumn{2}{c|}{ DINÁMICA DE LA } \\
TAREA
\end{tabular}

Tabla I. Tabla para el registro de tareas.

\section{RESULTADOS OBTENIDOS}

En un análisis cuantitativo previo (Llamazares, Ríos y Buisán, 2013), hemos constatado que la ACP, a pesar de su importancia, tiene escasa presencia en actividades de comprensión lectora. En esta ocasión, queremos aportar una visión de cariz cualitativo, con el fin de mostrar cómo se moviliza esta estrategia en función del objetivo que tiene el docente con la actividad planteada y ver cómo se distribuye teniendo en cuenta el tipo de texto.

Un análisis cualitativo de nuestras observaciones nos ha permitido establecer cuatro categorías, tomando como eje de análisis la finalidad de la estrategia, es decir, fijándonos en el objetivo que el docente o los niños persiguen con el uso de la misma. Es obvio que el contexto y la finalidad de la propia lectura condicionan la necesidad de hacer presentes saberes disponibles con anterioridad a la actividad lectora. Las cuatro categorías o finalidades con que se usa esta estrategia en nuestras observaciones son:

1) Activación de conocimientos temáticos. Se activan conocimientos previos sobre un tema para, apoyándose en ellos, introducir un concepto nuevo o reelaborar uno ya existente. De las 18 veces que ha aparecido la estrategia ACP en nuestras observaciones, en 9 ocasiones se ha utilizado para activar conocimientos temáticos: en 8 ocasiones antes de leer un texto expositivo o informativo, y solo en una antes de leer un texto narrativo, tanto en actividades consideradas por los docentes como específicas de comprensión lectora como no específicas.

La siguiente secuencia fue observada en un colegio de León, en $2^{\circ}$ curso de Educación Primaria (30/04/2010): antes de explicar el "sector servicios", la maestra (M) recuerda y activa conocimientos sobre otros sectores que han visto previamente, para que el nuevo concepto (el sector servicios) encaje: 
M (recordando lo explicado el día anterior): -En la página 41 había dibujos de tres profesiones. ¿Cuáles eran, Dani?

Dani: -Pescador, ganadero y agricultor.

M: -iQué sacan estos profesionales?

Niños: -El ganadero saca leche.

M: -Bien, porque ordeñan la vaca y sale la leche.

La M dirige la conversación sobre los productos que produce el ganadero, el agricultor...

M: $-i Y$ el pescador? Que no es el pescadero. ¿De dónde saca los productos?

Niños: -Del mar.

M: -El pescador, el ganadero, el agricultor llevan sus productos hacia otros sitios. ¿A dónde llevan sus materias primas?

Niño: -Al supermercado.

La $\mathrm{M}$ les hace razonar para que comprendan que antes de llegar al supermercado, las materias primas pasan por distintos tipos de fábricas. Luego hablan sobre el proceso de la leche: la M busca la precisión en la expresión (un niño dice que el ganadero le quita la leche a la vaca y la $\mathrm{M}$ le corrige: quitar la leche, no, es ordeñar la vaca), vocabulario referido a productos derivados de la leche que se lleva a la fábrica: quesos, yogur, nata, batidos, helados, mantequilla. Mientras hablan para que los niños pongan de manifiesto sus conocimientos, la $\mathrm{M}$ va haciendo un esquema en el encerado para que los niños comprendan las tareas de cada profesional: ganadero $\rightarrow$ leche

Fábrica $\rightarrow$ queso, yogur, nata...

Luego repasan el proceso de la carne porque, dice la maestra, "El cerdo no tiene jamón serrano según se mata, tiene que haber un proceso.": animales (ganadero) $\rightarrow$ mataderos $\rightarrow$ productos curados (lomo, jamón, cecina, jamón york...).

La M pide más materias primas. Un niño dice el acero.

M: -Muy importante, el acero. Vamos a centrarnos en el acero (y repasan objetos que pueden hacerse con acero). Pero hay otros tipos de trabajos que no son fábricas o trabajadores de tierra, de campo o del mar. Es lo que se llama de servicios; no trabajan ni en el campo, ni en el mar, ni en una fábrica (la $\mathrm{M}$ explica varias veces este concepto). Todos vamos a pensar en trabajos que dan servicios. Pensad.

Muchos niños levantan la mano. La M pide que le digan profesiones del sector servicio y razones por las que pertenecen a ese sector, mostrando, grosso modo, qué hacen para ayudarnos. Por ejemplo:

Juan: -Taxista

M: -¿El taxi nos da un servicio? ¿Lo encontramos por nuestro barrio? 
Cuando argumentan, la $\mathrm{M}$ quiere que se den cuenta de que dan un servicio. De esa manera salen cartero, médico, farmacéutico, profesora, piloto, camarero, bombero, cocinero. Después de pedirles que recorten, en sus casas, imágenes que representen a personas que estén trabajando en el sector servicios, pasan a leer un texto expositivo (lectura para aprender) cuyo título es "El trabajo del sector servicios". Es decir, la maestra ha estado buscando los conocimientos previos del alumnado para, partiendo de ellos, explicar este contenido.

Es habitual observar secuencias semejantes a esta que tienen lugar antes de leer un texto cuyos contenidos se podrían hacer corresponder básicamente con la materia de Conocimiento del Medio (los materiales sólidos, los bosques, el gato, el cuerpo humano...), tanto en $2^{\circ}$ como en $3^{\circ}$ de Educación Primaria, como la siguiente intervención (registrada en $3^{\circ}$ en un colegio de Cataluña, 27/05/2011). Antes de trabajar un contenido sobre la aparición de otra australopitecus, trabajo en el que van a manejar un texto expositivo, un vídeo y una noticia, la maestra recuerda conocimientos que ya tienen para asentar unos nuevos. La tarea final será relacionar ambos: comparar los datos que leyeron sobre el primer Australopitecus Afarensis con los del segundo.

La maestra (M) hace preguntas sobre una imagen para activar los conocimientos previos que ya han trabajado en clase.

M: -¿Recordáis cuando trabajamos los Australopitecus Afarensis? ¿Dónde habían aparecido? ¿En qué parte de África?

Alumnado: -Etiopía.

M: - ¿Dónde está, al norte o al sur?

Al: -Al este, en la zona de los lagos.

M: -Os daré una hoja con una austrolopitecus muy famosa. ¿Quién recuerda cómo se llamaba?

Al: - Lucy

M: -¿Qué os pido? Que leáis esto y subrayéis las cosas más importantes, ¡no todo!

En una ocasión, hemos recogido cómo, para explicar un contenido matemático las medidas de longitud-, se activaron conocimientos previos: medir los palmos de una mesa o el ancho de la clase utilizando los pies para hacer ver a los niños la necesidad de utilizar unidades estándar de medidas y llegar al decímetro (concepto nuevo) descomponiendo lingüísticamente el término y apoyándose en una unidad ya conocida (el metro).

En cuanto al tipo de texto, son, en su mayoría, textos expositivos, textos para aprender. En una ocasión, en una observación realizada en un colegio de Cataluña, en tercer curso (01/06/2011), se han utilizado textos periodísticos: 
La M presenta la actividad y les comenta que trabajarán en grupo. Les dice que trabajarán sobre "tiendas ecológicas". Les pregunta qué quiere decir eso; qué tipo de tiendas serán. Comentan con el grupo clase el significado de tienda ecológica. También recuerdan la fábrica ecológica que visitaron. Todos comentan en voz alta respetando los turnos de palabra. Tras esta puesta en común, la $\mathrm{M}$ da la consigna:

M: Cada grupo tendrá una serie de titulares con distintos cuerpos de noticia. Tendréis que elegir qué noticia corresponde a cada titular. Posteriormente tendréis que rellenar la ficha (nombre tienda, palabras clave, ventajas que ofrece la tienda).

Solo en una ocasión hemos visto activar conocimientos previos temáticos con un texto narrativo. El objetivo, en este caso, es leer para practicar la lectura en catalán. La observación tuvo lugar en un colegio de Cataluña, en tercer curso (17/05/2010):

M: Ahora repartimos los libros y libretas de catalán. Por favor, en la pizarra pone 'Lectura pág. 114'. El último día leímos 'El Zoo d'en Pitus'. Antes de comenzar, ¿de qué creéis que irá la lectura por la imagen?

Los niños miran el libro y van haciendo comentarios. La maestra los anima y les pregunta qué imágenes ven, qué dice el cartel del dibujo... La maestra continúa preguntando qué niños han ido al zoo y les recuerda que fueron con la escuela.

Antes de leer la maestra les habla del autor del libro, les dice que 'El zoo d'en Pitus' tuvo mucha fama y que este trozo es una parte del libro.

2) Activación de conocimientos previos para realizar una actividad. Se activa un conocimiento previo que se necesita para poder realizar actividades que se proponen después de haber leído un texto. El uso de la estrategia ACP con esta finalidad la hemos observado cuatro veces, dos veces con textos narrativos (uno de ellos poesía narrativa) y dos veces con textos expositivos, siempre después de haber leído el texto y en tareas consideradas por los docentes tanto específicas de comprensión lectora como no específicas.

Con textos narrativos hemos observado dos secuencias. En la primera (observada en un colegio de León, en $2^{\circ}$ curso, el 21/04/2010), después de haber leído una poesía narrativa, el libro propone para trabajar la comprensión de la misma, entre otras, una actividad de completar rimas: se formula una pregunta de idéntica estructura con variación en la última palabra (¿Dónde está la gallina / el conejo / el ratón / el zapato?) para que, observando la ilustración, respondan a ella en forma de rima. La ilustración contiene los elementos que necesitan para hacer la rima, situados 
estratégicamente (gallina detrás de una cortina, conejo cerca de un espejo, etc.). Antes de que los niños se pongan a realizar la tarea (pero después de haber leído el texto), la maestra recuerda el concepto de rima:

M: -¿Qué es eso de rima, María?

María: -Que rima con todo.

M: -Pero, ¿qué es eso de rima?

María: -Que suenan casi igual.

M: -Exactamente. ¿Quién me dice dos palabras que riman?

Rodrigo (ya ha observado en el libro lo que tenían que hacer): -Gallina con cortina.

M: - ¿Quién se atreve a decirme dos frases que rimen? (Intervienen varios niños)

María: -Me voy a la China ly se me olvidó la mochila.

Me voy a Japón/ y se me olvidó el jabón.

Miguel: Yo me sé otra. Me fui a la China / y se me olvidó la gallina.

Después de los ejemplos, pasan a las frases que les pide el libro, lo resuelven primero de forma colectiva oralmente, la $\mathrm{M}$ recalca para que se fijen al escribir en las bes, las uves, los acentos...

En la segunda secuencia, observada en otro colegio de León, pero esta vez en tercer curso (18/05/2011), después de leer un texto narrativo, la $M$ formula una pregunta para que los niños aporten sus conocimientos acerca de la función que han tenido los burros (y que se completa con la explicación de vocabulario). La maestra consideraba que era una tarea específica de comprensión lectora:

(...) N2: Cuando llevó el burro en el saco.

M: ¿Por qué?

N2: Porque normalmente se va en el burro.

M: ¿Para qué se utilizaban los burros?

N3: De carga.

$\mathrm{M}:$ ¿Qué significa de carga?

N3: Para llevar cosas.

M: ¿Y hay muchos burros ahora? (Los niños responden a coro que no)

M: Están en peligro de...(Los niños responden a coro: extinción)

M: ¿Y qué significa extinción?

N4: extinguirse

M: Pero con otras palabras... 
N5: Que si se siguen muriendo van a desaparecer.

N6: También están en peligro de extinción el lince ibérico y el lobo ibérico.

En cuanto a los textos expositivos, en un caso (observado en un colegio de Almería, en tercer curso, el 17/03/2011) el docente recuerda el concepto de polisemia para que los discentes realicen varios ejercicios del libro de lengua. En el otro caso, hemos recogido en un colegio del País Vasco (tercer curso, 16/12/2010) una secuencia en la que se lee en voz alta un ejercicio que requiere que los alumnos recuperen y utilicen las escalas de las distintas magnitudes que han trabajado previamente para calcular por ejemplo, cuántos gramos hay en un $\mathrm{kg}$. Se hace en euskera $\mathrm{y}$, aunque la lectura de la consigna se ha dado por buena, hay muchas dificultades para entender qué es lo que tienen que hacer en el ejercicio. La profesora reformula la pregunta, pero termina recuperando la historia de la clase y hablando de ejercicios similares que se hicieron anteriormente (utilizando equivalencias de medidas $1 \mathrm{~kg}=1000 \mathrm{~g}$ ). La profesora activa conocimientos previos ayudándose de una tabla de equivalencias de varias magnitudes (peso, volumen) dibujada en el encerado y les hace preguntas que ilustran cómo se utilizan esas tablas.

3) Activación de conocimientos textuales. Se activan conocimientos previos sobre características textuales. De las 18 veces que ha aparecido la estrategia ACP en nuestras observaciones, en tres de ellas se ha utilizado para activar conocimientos textuales: dos veces con un texto informativo (en uno de ellos también se activaban conocimientos temáticos) y una con un texto poético, siempre antes de leerlo y en tareas consideradas tanto específicas de comprensión lectora como no específicas.

La siguiente secuencia fue recogida en tercer curso de un colegio de Cataluña el 26/05/2011. Antes de la lectura de un texto expositivo/informativo sobre los bosques, la maestra anticipa el tema, lo relaciona con las experiencias propias de su alumnado para activar sus conocimientos previos sobre ese tema y no se olvida de fijar, de antemano, el tipo de texto al que se van a enfrentar:

La M introduce el tema aprovechando la excursión que hicieron la semana anterior a un bosque conocido como la Fageda d'en Jordà. Les pregunta por el nombre de la comarca, por el nombre del bosque, y les dice que hoy hablarán de bosques.

Les indica que primero observarán qué saben de los bosques entre todos. Los niños expresan sus conocimientos en voz alta y respetando el turno de habla. 
La M reorganiza, sintetiza los comentarios y aportaciones de los niños en palabras clave que anota en la pizarra en forma de mapa conceptual; también anota las dudas que surgen en la clase, para comprobar si, posteriormente, las resolverán con la lectura. Por último, la $\mathrm{M}$ realiza una pregunta a todo el grupo clase:

$\mathrm{M}$ : -Si es un texto que habla de los bosques, ¿qué tipo de texto será? (Los alumnos comentan el tipo de texto que no será: poema, novela, cuento...).

Niña: ¡Texto informativo! (La M confirma y pasan a la lectura).

En esta otra, la profesora les muestra un folleto y les explica que ayer cogió este díptico de la biblioteca de su población (texto real, por tanto). A continuación les pregunta qué suponen ellos que contiene ese díptico. Fue recogida en un colegio de Cataluña, en tercer curso (el 25/05/2011).

M: -¿De qué puede ir este folleto?

Alumnos: -Información sobre la biblioteca

M: - ¿Qué clase de información?

Al: -Actividades de la biblioteca

M: -iAlguien tiene una idea diferente?

Después muestra el contenido del díptico por medio del cañón en la pizarra digital

La última secuencia en la que hemos observado una activación de conocimientos previos sobre el tipo de texto, la hemos recogido en un colegio de León, en tercer curso (25/05/2011). Se disponen a iniciar una unidad titulada Poemas, y antes de leer los textos poéticos incluidos en la misma, la maestra trata de que recuerden las poesías que, sobre Castilla, escribió Antonio Machado y que leyeron al comienzo del curso. Además, la lectura de una de las poesías (La niña que se va al mar de Rafael Alberti) viene precedida por una activación de conocimientos previos:

M: La siguiente poesía ya la hemos leído ¿Quién recuerda algo de Alberti? Vivió en la misma época de Federico García Lorca y era un hombre peculiar. Lucía una melena larga...

4) Activación de conocimientos previos para seguir leyendo un texto. Se activan conocimientos previos para continuar con el hilo argumental de un relato que 
se ha empezado a leer en un momento anterior: se trata de la hora de lectura (esto es, leer para practicar la lectura). Con esta finalidad hemos visto utilizar esta estrategia en dos ocasiones (de 18), siempre con textos narrativos y en tareas que los docentes consideran específicas de comprensión lectora. La secuencia que transcribimos se observó en un colegio de Madrid (18/05/2011), en tercer curso:

Cogen su libro de lectura y, antes de comenzar un capítulo nuevo, recuerdan lo que ya han leído.

M: -Página 88, página 85, perdón. En el libro vamos a empezar un capítulo nuevo, pero entre todos. Vamos a recordar, Muna.

Muna: -Claude era un niño que iba al cole y tenía una profe que se llamaba...

Hana:- $M^{a}$ Dolores

Muna: $-Y$ un día vinieron inmigrantes y se hicieron grupos

M: ¿Qué pasó, Paula?

Paula: -Un día le pegaron y los padres pusieron una denuncia

M: -¿Y quién era $M^{a}$ Dolores?

AA: -La profe

Maestra: -El libro habla, entonces, de inmigrantes

Empiezan a leer el capítulo nuevo. Los niños están en silencio mientras se hace la lectura colectiva. La lectura se interrumpe continuamente para recuperar datos sobre los personajes, elementos de la narración, cuestiones de ortografía, léxico, geografía y ciudadanía (las amistades). Suele recurrir a las experiencias de los niños. Por ejemplo:

M: -Marta lee... Sigue Celia... (y los niños leen cuando les nombra)

M: -¿Quién era Félix? ¿Quién se acuerda?

Marta: -Su hermano

M: -¿Por qué va a su habitación?

Hana: -Para ver a Paula

M: -¿Por qué?

Hana: -Porque llegó con el ojo morado

M: Sigue, Marta

Los docentes que están al frente de las aulas que hemos seguido, utilizan diversas ayudas para facilitar a los niños la activación de sus conocimientos previos en cualquiera de las categorías establecidas:

- Contextualizar la actividad, lo que implica hacer explícitos los objetivos de la lectura: si van a leer para practicar la lectura, si necesitan buscar una información en el texto, si van a tener que rellenar una ficha con datos de la lectura... También se 
contextualiza la actividad proporcionando información general sobre lo que se va a leer, avanzando o anticipando el tema del texto (acompañado incluso de un dibujo en la pizarra) y quién lo escribió o, y esto es menos frecuente, especificando el tipo de texto que se va a leer. En el siguiente ejemplo, extraído de un colegio del País Vasco, en tercer curso (01/04/2011) se anticipa el tipo de texto que van a leer pero sin solicitar justificaciones (¿por qué es una noticia y no un cuento?):

Deben leer un texto sobre el BIG BEN de Londres, aunque también figuran otras ciudades del mundo relacionadas con edificios emblemáticos. Antes de empezar a leer el texto, la $\mathrm{M}$ les hace preguntas exploratorias partiendo del título:

M: -¿Alguien sabe qué es el Big Ben? ¿Dónde está?

Los alumnos van respondiendo y se van ubicando en el tema del texto. Luego hace lo mismo con las demás ciudades. Por último les pregunta si lo que van a leer es un cuento o una noticia. Responden que una noticia

- Elementos textuales como las ilustraciones. Es un recurso habitual entablar una conversación partiendo de una imagen para activar conocimientos previos, como se muestra en la siguiente secuencia recogida en tercer curso (17/05/2011) en un colegio de Cataluña:

Los niños cogen, por indicación de la M, el libro de catalán y deben observar durante un minuto, en silencio, una imagen en la que hay un gato con los ojos cerrados lamiéndose una patita. A partir de esa imagen, activan y anticipan conocimientos previos a la lectura: contestan unas preguntas a partir de una foto $\mathrm{y}$ aprovechan una mini poesía que tienen en el rincón de poesía que trata sobre el tema de la foto. El objetivo es practicar y aprender la lengua catalana.

El título es un elemento del texto que claramente sirve para anticipar el tema, pero no hemos visto que se usen otros elementos textuales (subtítulos, partes del texto, subrayados, palabras destacadas o clave...) para la ACP.

- Animar a los alumnos a que expongan lo que conocen sobre el tema. Ayuda mucho que, además de dar una información, se les pidan las razones que relacionan esa información con el tema porque para la persona que interviene pueden ser evidentes pero no lo son tanto para los que escuchan. Se favorece así un discurso argumentativo. 


\section{- Esquemas, por ejemplo:}

-Marcar en la pizarra la longitud de un metro e invitar a dividirlo en diez partes iguales para llegar al concepto de decímetro.

-Escalas matemáticas sobre medidas de longitud, volumen...

-Plasmar en un cuadro sinóptico, mapa conceptual sencillo o cualquier otro tipo de esquema que haga visibles las relaciones de las aportaciones del alumnado sobre el tema que van a tratar. Se trata de una labor docente importante porque las informaciones que proporcionan los alumnos, a menudo inconexas, se reorganizan, eliminando lo no pertinente, y se centran en el tema que les ocupa.

Nuestras observaciones dan como resultado que la estrategia de activar conocimientos previos se distribuye de manera distinta en función del tipo de texto y del objetivo que se persigue con la lectura (puede verse una tabla completa en Llamazares, Ríos y Buisán, 2013). De las 18 veces que ha aparecido esta estrategia en nuestras observaciones, en 12 ocasiones el texto de partida era de tipo expositivo (fundamentalmente de la materia Conocimiento del Medio) o informativo. En 4 ocasiones se activaban conocimientos previos ante un texto narrativo y dos veces lo hemos observado con textos poéticos. Sólo en el caso de que se activen conocimientos previos para que los niños puedan resolver una actividad, la estrategia surge inmediatamente antes de resolverla, pero siempre después de la lectura; en el resto de las ocasiones, como parece lógico, la activación de conocimientos previos se produce antes de la lectura (y en dos ocasiones también lo hemos visto durante) y se hace tanto con actividades que los docentes consideran específicas de comprensión lectora como no específicas.

Según la finalidad con la que se va a leer, la mitad de las ocasiones se activan conocimientos previos sobre el tema del que tratará la lectura con el objetivo de aprender un concepto nuevo. En un 16,6\% se activan conocimientos previos relativos al tipo de texto y en un $11,1 \%$ se hace para seguir leyendo un relato, en este caso, solo con textos narrativos. En un $22,2 \%$ se activan conocimientos previos para resolver una actividad derivada de la lectura previa de un texto.

En síntesis, encontramos que la activación de conocimientos previos es una estrategia cuya distribución varía en función del tipo de texto y del objetivo de la lectura: se asocia fundamentalmente a textos expositivos, explicativos, con los que se pretende que el alumno amplíe conocimientos. Por esta razón, se manifiesta cuando se usa la lectura para aprender nuevos conceptos.

\section{DISCUSIÓN DE RESULTADOS}

El análisis muestra que, a pesar de ser una estrategia clave, no se obtuvieron tantos ejemplos de ACP como cabía esperar, lo que parece indicar que la comprensión lectora se concibe como algo que hay que trabajar después de leer. Aunque la distinción entre estrategias para utilizar antes, durante o después de la lectura (Solé, 
2006) puede llegar a ser artificiosa, dado que varias de ellas son intercambiables, nos permite afirmar que las estrategias para trabajar la comprensión lectora deben estar presentes a lo largo de toda la actividad y que la ACP es una estrategia ad hoc para los momentos previos a la lectura.

Por otra parte, cuando surge, lo hace asociada fundamentalmente a tareas destinadas a aprender contenidos nuevos, con textos fundamentalmente de tipo expositivo (o informativo). Si los niños han de leer para aprender, el docente sí inicia el acercamiento al texto activando conocimientos relacionados con el contenido del texto que van a trabajar. Se persigue que la información contenida en el texto se integre en las estructuras de conocimiento del alumnado para enriquecerlas y reorganizarlas. En cambio, cuando los niños leen para aprender a leer, generalmente con textos narrativos (literarios o no), rara vez se activan los conocimientos previos; como mucho, el docente adelanta que van a leer un "cuento".

Estas diferencias dejan traslucir una concepción diferente de la lectura y de sus objetivos según el tipo de texto (Llamazares, Ríos y Buisán, 2013: 321): la lectura de textos expositivos, que sirven para aprender algo nuevo, requiere del establecimiento de continuidades o enganches con conocimientos anteriores para poder entender la nueva información. En cambio, la lectura de textos narrativos, que se utilizan fundamentalmente para practicar la lectura, dejando a un lado la comprensión del texto, no necesitaría de ninguna activación de conocimientos previos.

Hemos encontrado que esta diferente concepción se manifiesta en la alta frecuencia con que se utiliza la ACP para activar conocimientos temáticos (un 50\%) frente a las escasas veces (un 16\%) que se encuentra una activación de conocimientos textuales. Es un dato preocupante porque Vidal-Abarca y Martínez (1998) señalan, además, que la intervención pedagógica dirigida a activar conocimientos previos no debería focalizarse en contenidos específicos (temáticos), sino que debería dirigirse hacia los esquemas de interpretación (o constructos psicológicos) que subyacen a la comprensión. Hay trabajos que demuestran que la exposición al material impreso, la familiaridad con la lengua escrita y el reconocimiento de las características de diversos géneros discursivos (por ejemplo de la estructura narrativa o de la definición y la descripción) inciden en el desarrollo de la comprensión lectora (Tolchinsky, 1993). Si la estructura del texto ofrece indicadores esenciales que facilitan su interpretación, la ACP textual debería utilizarse con tanta frecuencia al menos como la ACP de contenidos temáticos, también con textos narrativos donde hemos visto que la $\mathrm{ACP}$ se reduce prácticamente a recordar el argumento del relato que se había empezado en otro momento. El acercamiento a este tipo de textos debería contemplar también una ACP textual para que el lector aprenda a enfrentarse a ellos y no solo realice una lectura literal que no le aportará beneficios psicológicos ni personales, poniendo en entredicho la educación literaria de los niños (Llamazares, Ríos y Buisán, 2013: 322).

La ACP debería iniciarse con información explícita sobre qué se va a leer y para qué, esto es, los objetivos de la lectura. Se trata de motivar al alumnado haciéndole 
ver que es capaz de enfrentarse a un texto distinguiendo entre lo que ya sabe y lo que puede aprender con su lectura. Señala Solé $(2006,35)$ que el tema de los objetivos que el lector se propone lograr con la lectura es crucial, porque determina tanto las estrategias responsables de la comprensión como el control que de forma inconsciente va ejerciendo sobre ella, a medida que lee.

\section{CONCLUSIONES}

Para leer comprendiendo es necesario recurrir al conocimiento del mundo y a los conocimientos derivados del texto (forma y contenido) y dominar no sólo las habilidades de descodificación sino también una serie de estrategias que permiten el procesamiento activo del sentido y de los significados. Hemos establecido la frecuencia de aparición de la ACP y hemos descrito cómo se usa, porque el objetivo de este trabajo es mostrar a los docentes, especialmente a aquellos en formación, lo que sucede en una muestra de aulas para guiarles en el análisis de situaciones de enseñanza-aprendizaje de la comprensión lectora.

No pretendemos afirmar que solo sucede lo que se ha descrito, pero sí que lo que se ha descrito sucede y de los resultados se pueden obtener una serie de pautas para "mirar al aula". Como formadores de futuros docentes creemos, además, que de estos resultados pueden obtenerse varias implicaciones didácticas. En primer lugar, creemos que es necesario convencerse de que las estrategias se enseñan, por lo que se debe planificar la enseñanza de la comprensión lectora para poder utilizar estrategias que no surgen espontáneamente: la $\mathrm{ACP}$ es una de esas estrategias que no surge de manera casual ni por efecto de la maduración; el análisis de los datos demuestra que su presencia es escasa en las aulas y que no siempre se motiva al alumnado, haciendo explícitos los objetivos de la lectura. Cuando el profesor intenta dar alguna pista a sus alumnos para abordar el texto está construyendo "contextos mentales compartidos" (Edwards y Mercer, 1988). Al combinar esta información compartida con los requerimientos -objetivos que se pretenden- de la lectura, el alumno lector posee, antes de iniciarla, un esquema o plan de lectura que le dice qué tiene que hacer con ella y qué sabe él y qué no sabe acerca de lo que va a leer. Por tanto, activar conocimientos previos supone buscar en la mente del lector informaciones, experiencias o sensaciones que puedan ser conectadas de forma coherente y personal con los nuevos conocimientos o informaciones que son proporcionados en el texto.

Por otro lado, hemos establecido cómo se distribuye la ACP en función del tipo de texto que se aborde y de la finalidad de la lectura, lo que nos hace ver la necesidad de elegir cuidadosamente los textos con los que trabajar la comprensión lectora y de no limitarse a activar conocimientos de tipo temático, cuando tan importantes son también los de tipo textual, dado que las diferentes estructuras textuales superestructuras según Van Dijk-imponen restricciones a la forma como se organiza la información escrita. En tareas específicamente destinadas a trabajar la comprensión lectora con textos narrativos (fundamentalmente), el docente no debería 
limitarse a practicar la lectura, sino que debería dotarla de un sentido. Dado que los textos expositivos parecen favorecer el uso de la ACP, pensamos que sería conveniente formar al alumnado para que pueda seleccionar, analizar y utilizar este tipo de textos para el desarrollo de la comprensión lectora.

Creemos, en suma, que la investigación didáctica a partir de grandes muestras permite obtener resultados generalizables que proporcionan las bases sobre las que asentar el conocimiento teórico de maestros en formación; y las investigaciones realizadas sobre un volumen más asequible de datos permiten mostrarles la realidad de las aulas, para que aprendan a analizar y aplicar, construyendo así su conocimiento práctico.

\section{BIBLIOGRAFÍA}

ACQUARONI MUÑOZ, Rosana (2004): "La comprensión lectora", en Vademécum para la formación de profesores. Enseñar español como segunda lengua (L2)/Lengua extranjera (LE), SÁNCHEZ LOBATO, J. e I. SANTOS GARGALlO (dirs), Madrid, Sociedad General Española de Librería, 943-964.

ADAM, Jean-Michel (1985): "Quels types de textes?", en Français dans le monde, 192, 39-43.

Altava, Vicenta, F. Gimeno, I. PÉrez, I. Ríos e I. M. Gallardo (2006): "El análisis de las situaciones de aula como instrumento de la formación del profesorado", en Diálogo e investigación en las aulas, CAMPS, A. (coord.), Barcelona, Graó, 263-285.

ANGUERA, Teresa (1983): Manual de prácticas de observación, México, Trillas.

BRUNER, Jerome (1988): Realidad mental y mundos posibles: los actos de la imaginación que dan sentido a la experiencia, Barcelona, Gedisa.

COLOMER, Teresa, A. CAMPS (1996): Enseñar a leer, enseñar a comprender, Madrid, Celeste/MEC.

De Vega, Manuel, M. Carreiras, M. Gutiérrez-Calvo, y M. AlonsoQUECUTY (1990): Lectura y comprensión. Una perspectiva cognitiva, Madrid, Alianza Editorial.

EDWARDS, Derek y N. MERCER (1988): El conocimiento compartido. El desarrollo de la comprensión en el aula, Barcelona, MEC.

FAYOL, Michel (1991): "Stories: a psycholinguistic and ontogenetic approach to the acquisition of narrative abilities", en Language Bases... Discourse Bases, PIÉRAUT-Le-Bonniec, G. y M. Dolitsky (eds.), Amsterdam, John Benjamins, 229244.

LLAMAZARES, Teresa, I. Ríos, y C. BUISÁN (2013): "Aprender a comprender: actividades y estrategias de comprensión lectora en las aulas", en Revista Española de Pedagogía, 255, 309-326.

MendOZA Fillola, Antonio (coord.) (1998): Conceptos clave en didáctica de la lengua y la literatura, Barcelona, Horsori. 
NAVARRo, Juan José y J. MORA (2009): "Metaconocimientos y comprensión de textos", en Investigación en la escuela, 69, 99-113.

PALINCSAR Annemarie y A.L. BROWN (1984): "Reciprocal teaching of comprehension-forstering and comprehension-monitoring activities", en Cognition and instruction, 1 (2), 117-175.

PERRUSI BRANDAO, Ana Carolina y J. OAKHILL, (2005): “"How do You Know this Answer?' - Children's Use of Text Data and General Knowledge in Story Comprehension", en Reading and Writing, 18, 687-713.

SÁNCHEZ MiguEL, Emilio (1998): Comprensión y redacción de textos. Dificultades y ayudas, Barcelona, Edebé.

SÁnchez RodrígueZ, Susana, T. LlamaZAREs PRIETO y M.D. Alonso-Cortés FRADEJAS (2011): "Del aprendizaje inicial de la lectura y la escritura al aprendizaje de la comprensión lectora", en La investigación en Didáctica de la Lengua y la Literatura. Situación actual y perspectivas de futuro. NúÑEZ DELGADO, P. y J. RIENDA, Madrid, Sedll, 471-484.

SÁNCHEZ, Susana y M.D. ALONSO-CORTÉS (coords.) (2012): Aprendizaje inicial de la lengua escrita: prácticas docentes y conocimientos de los alumnos, Monográfico de Cultura y Educación, 24/4.

SiM-SIM, Inés y F. VIANA (2007): Para a avaliação do desempenho de leitura, Lisboa, Gabinete de Estadística e Planeamento da Educação (GEPE).

SolÉ, Isabel (2006): Estrategias de lectura, Barcelona, Graó.

TOLCHINSKY, Liliana (1993): Aprendizaje del lenguaje escrito. Procesos evolutivos e implicaciones didácticas, Barcelona, Anthropos.

TOLCHINSKY, Liliana e I. SOLÉ (2009): "Las condiciones del aprendizaje de la lengua escrita", en Infancia y Aprendizaje, 32 (2), 131-140.

VAN DIJK, Teun y W. KINTSCH (1983): Strategies of Discourse Comprehension, New York, Academic.

VIDAL-ABARCA, Eduardo y G. MARTínez RiCo (1998.): “¿Por qué los textos son difíciles de comprender? Las inferencias son la respuesta", en Textos de didáctica de la lengua y de la literatura, 16, 85-97.

VIDAL-ABARCA, Eduardo, "10 claves para aprender a comprender", en http://www.leer.es [consultado el 20 de junio de 2011].

WELLS, Gordon (1988): Aprender a leer y escribir, Barcelona, Laia. 